\title{
Thermal behaviour of citric acid and isomeric aconitic acids
}

\author{
D. Wyrzykowski $\cdot$ E. Hebanowska $\cdot$ G. Nowak-Wiczk • \\ M. Makowski $\cdot$ L. Chmurzyński
}

Received: 9 June 2010/Accepted: 18 August 2010/Published online: 31 August 2010

(C) The Author(s) 2010. This article is published with open access at Springerlink.com

\begin{abstract}
Thermal decomposition of citric acid, transand cis-aconitic acid has been studied using the TG-MS, TG-FTIR and DSC techniques. The measurements were carried out in an argon atmosphere over a temperature range of 293-673 K. The influence of the acid structures and configurational geometry on stability of the transition products and pathways of thermal transformations of the studied compounds studied is discussed.
\end{abstract}

Keywords Citric acid · Trans-aconitic acid · Cis-aconitic acid $\cdot$ Thermal decomposition

\section{Introduction}

Citric acid, 2-hydroxypropane-1,2,3-tricarboxylic acid, is a natural compound occurring in human organisms and in plant and animal cells, generated during initial transformations in the Krebs cycle [1-3]. Since it is nontoxic, citric acid has found widespread application in the food industry as an antioxidant and preserving agent. It is also used in the metallurgical industry for cleaning metal surfaces prior to welding because it covers the metal surfaces with a protective coating. In the pharmaceutical industry, citric acid has been used as a stabilizer of active ingredients of preparations and as a flavouring additive in tablets.

Recently, interest in citric acid has grown owing to its use for the synthesis of nano-powders doped with rare earth metal ions, transition metals and others $[4,5]$. In the Pechini

D. Wyrzykowski $(\bowtie) \cdot$ E. Hebanowska · G. Nowak-Wiczk ·

M. Makowski · L. Chmurzyński

Faculty of Chemistry, University of Gdańsk, Sobieskiego 18, 80-952, Gdańsk, Poland

e-mail: daro@chem.univ.gda.pl method, the acid is used as a non-polymeric filler for size modification and porosity control of nano-powders. In this method, citric acid is removable by either heat treatment or thermal decomposition, without affecting the properties of a material [6-8].

Barbooti and Al-Sammerrai [9] reported on the thermal decomposition of citric acid. As stated, the decomposition is preceded by melting followed by dehydration and decarboxylation processes resulting in the formation of methyl maleic anhydride.

In order to acquire better insight into thermal transformations of citric acid, we have presented the broader characteristics of its thermal behaviour. To be able to do this, we have examined the intermediate dehydration products of the acid, trans-aconitic acid (trans-propene1,2,3-tricarboxylic acid) and its cis-isomer, cis-propene1,2,3-tricarboxylic acid. In our work the results of the TG-FTIR, TG-MS and DSC analyses of the three acids studied are presented.

\section{Experimental}

Materials

All reagents: citric acid, $\mathrm{C}_{6} \mathrm{H}_{8} \mathrm{O}_{7}$, (ACS reagent, $\geq 99.5 \%$ ), trans-aconitic acid, $\mathrm{C}_{6} \mathrm{H}_{6} \mathrm{O}_{6},(\geq 98 \%)$ and cis-aconitic acid, $\mathrm{C}_{6} \mathrm{H}_{6} \mathrm{O}_{6},(\geq 98 \%)$ were purchased from Aldrich Chemical Corp. and were used without further purification.

Methods

The TG-FTIR analyses in argon (Ar 5.0) were run on a Netzsch TG 209 apparatus coupled with a Bruker IFS 66 spectrometer (range 298-673 K, Al crucible with a small 
central hole, sample mass $5-10 \mathrm{mg}$, heating rate 5,10 , $15 \mathrm{~K} \mathrm{~min}^{-1}$, flow rate of the carrier gas $15 \mathrm{~mL} \mathrm{~min}{ }^{-1}$ ). The TG-DSC-MS measurements in argon (Ar 5.0) were run on a STA 449 F3 Jupiter ${ }^{\circledR}$ thermal analyzer (Netzsch) coupled with a QMS 403 C Aëolos ${ }^{\circledR}$ quadrupole mass spectrometer (range $308-673 \mathrm{~K}, \mathrm{Al}$ crucible with a small central hole or open $\mathrm{Al}_{2} \mathrm{O}_{3}$ crucible, empty crucible as a reference, sample mass $5-10 \mathrm{mg}$, heating rate $5,10,15 \mathrm{~K} \mathrm{~min}^{-1}$, flow rate of the carrier gas $20 \mathrm{~mL} \mathrm{~min}^{-1}$ ). The DSC measurements were carried out in a model DSC 204 Netzsch calorimeter (range 298-673 K, Al crucible with a small central hole, empty $\mathrm{Al}$ crucible as a reference, sample mass 5-10 mg, heating rate $2,5,10 \mathrm{~K} \mathrm{~min}^{-1}$, flow rate of the carrier gas $20 \mathrm{~mL} \mathrm{~min}^{-1}$ ).

The DFT (density functional theory) method [10] with the B3LYP (Becke three-parameter hybrid exchange functional and the non-local correlation functional of Lee, Yang and Parr) functional $[11,12]$ and the $6-31+\mathrm{G}^{* *}$ basis set [13] were used to optimize the structures of the systems studied. Geometries of isolated fragments were fully optimized without symmetry constraints. At the energy minima (with real frequencies) of a particular species, the energy parameters of isomerization process of cis-aconitic anhydride into trans-aconitic anhydride were calculated at $450 \mathrm{~K}$ using the same level of theory. The $G$ values included changes at the zero-point energy (ZPE) and thermal corrections (vibrational, rotational and translational) to the enthalpy $(H)$ and entropy $(S)$. All calculations were performed using the Gaussian 03 program [14].

\section{Results and discussion}

The TG and DSC curves of the compounds recorded at a heating rate of $10 \mathrm{~K} \mathrm{~min}^{-1}$ in $\mathrm{Al}$ crucible are shown in Figs 1 and 2. The onset and the end decomposition temperature of citric acid, trans-aconitic acid and cis-aconitic acid determined by extrapolation are collected in Table 1 . As seen, citric and trans-aconitic acid exhibit a comparable thermal stability in contrast to cis-aconitic acid whose decomposition point is $60-70 \mathrm{~K}$ lower than that of the remaining compounds.

Decomposition of citric acid is preceded by its melting. The melting point was determined by DSC measurements and equals $433.9 \pm 0.2 \mathrm{~K}$ (average of eleven results \pm standard error).

The shape of the TG curves of citric acid suggests that a single-step process occurs. However, in the DSC curve, over the temperature range covering that step, there is a broad endothermic peak with two non-symmetric inflexions indicating a complex decomposition process. Extremal peak temperatures and enthalpy changes for particular

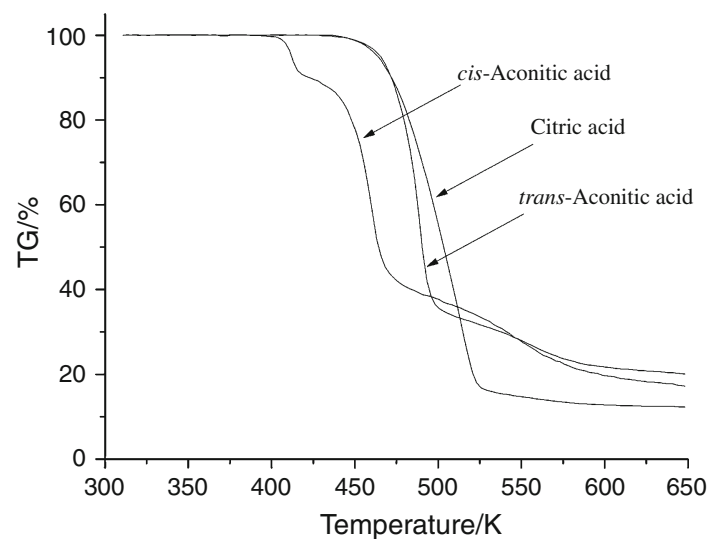

Fig. 1 TG curves of thermal decomposition of citric acid, transaconitic acid and cis-aconitic acid in argon, $\beta=10 \mathrm{~K} \mathrm{~min}^{-1}$

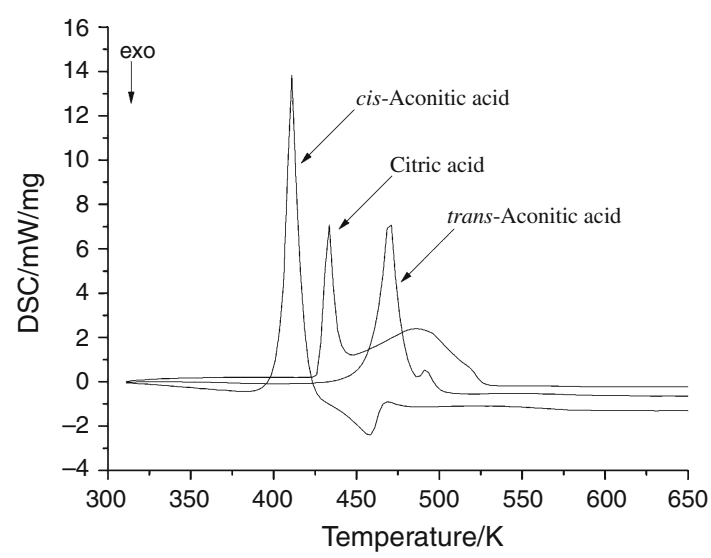

Fig. 2 DSC curves of thermal decomposition of citric acid, transaconitic acid and cis-aconitic acid in argon, $\beta=10 \mathrm{~K} \mathrm{~min}^{-1}$

Table 1 The onset and the end decomposition temperature of citric acid, trans-aconitic acid and cis-aconitic acid in argon, $\beta=5,10$ and $15 \mathrm{~K} \mathrm{~min}^{-1}$

\begin{tabular}{|c|c|c|c|c|c|c|}
\hline \multirow[t]{2}{*}{ Compound } & \multicolumn{2}{|c|}{$5 / \mathrm{K} \min ^{-1}$} & \multicolumn{2}{|c|}{$10 / \mathrm{K} \mathrm{min}^{-1}$} & \multicolumn{2}{|c|}{$15 / \mathrm{K} \mathrm{min}^{-1}$} \\
\hline & $T_{\text {onset }}$ & $T_{\text {end }}$ & $T_{\text {onset }}$ & $T_{\text {end }}$ & $T_{\text {onset }}$ & $T_{\text {end }}$ \\
\hline Citric acid & 475.8 & 521.0 & 485.3 & 534.3 & 495.3 & 544 \\
\hline trans-Aconitic acid & 477.3 & 504.4 & 488.1 & 518.7 & 501.7 & 526.7 \\
\hline \multirow[t]{3}{*}{ cis-Aconitic acid } & 404.9 & 420.2 & 415.1 & 430.8 & 422.0 & 441.1 \\
\hline & 447.5 & 466.2 & 461.1 & 478.9 & 472.1 & 485.9 \\
\hline & 527.2 & 577.9 & 541.5 & 600.0 & 550.4 & 613.4 \\
\hline
\end{tabular}

energetic effects accompanying heating of the compounds are shown on Table 2.

The inflexions in the DSC peak are probably due to overlapping of endothermic effects associated with decomposition of intermediate products formed when heating the sample (Fig. 2). Citric acid has been known to form thermodynamically stable complexes with various 
Table 2 Temperature and enthalpy changes for physicochemical transformations of citric acid, trans-aconitic acid and cis-aconitic acid in argon, $\beta=10 \mathrm{~K} \mathrm{~min}^{-1}$

\begin{tabular}{llc}
\hline Compound & $T_{\mathrm{p}} / \mathrm{K}$ & $\Delta H / \mathrm{kJ} \mathrm{mol}^{-1}$ \\
\hline Citric acid & 433.0 & 40.15 \\
& $433-794.2$ & 144.94 \\
trans-Aconitic acid & 471.4 & 87.77 \\
& 496.5 & 6.06 \\
cis-Aconitic acid & 407.7 & 86.55 \\
& 458.4 & -23.61 \\
\hline
\end{tabular}

$T_{\mathrm{p}}$ peak temperature, temperature at which a maximum of the thermal effect emerges

metal ions, including $\mathrm{Al}^{3+}$, in which it occurs as a tridentate ligand $[15,16]$. For this reason, to eliminate a catalytic influence of the aluminium crucible on thermal transformations of the acid, including the shape of the DSC curve, the experiment was performed in a corundum $\left(\mathrm{Al}_{2} \mathrm{O}_{3}\right)$ crucible. In this case, the inflexions in the DSC curve also emerged, this indicating a multi-step course in the decomposition of the acid. Accordingly, examination of both the TG and DSC curves shows unambiguously that the decomposition of the acid under comparable conditions cannot be regarded as a single-step process.

The trans-aconitic acid does not melt before decomposition. Its first step ending around $510 \mathrm{~K}$ is characterized by two endothermic events in the DSC curve. They are indicative of a complex process in spite of a single step-like shape of the TG trace. The rate of the first step in the decomposition of the acid is faster than the corresponding one of citric acid over an analogous temperature range. For comparison, maximum mass loss rates determined from the DTG curves, at a heating rate of $10 \mathrm{~K} \mathrm{~min}^{-1}$ in $\mathrm{Al}$ crucibles with a small central hole, are 18 at $513 \mathrm{~K}$ and $40 \% / \mathrm{min}$ at $489 \mathrm{~K}$ for citric and trans-aconitic acid, respectively.

Geometric configuration of the aconitic acid has a fundamental influence on the course of its decomposition. The cis-isomer is markedly less thermally stable than its trans counterpart. During the first step, the former loses one molecule of water to form cis-aconitic anhydride. This is demonstrated by a $9.8 \%$ mass loss (in TG curve) close to $10.3 \%$ as calculated for the loss of one water molecule, as well as by IR bands over the ranges 4000-3500 and $1750-1400 \mathrm{~cm}^{-1}$ assignable to water vapour. The dehydration step was further supported by ionic current intensities at $\mathrm{m} / \mathrm{z}=17$ and 18 , recorded over the temperature range studied.

The relatively thermally stable cis-aconitic anhydride undergoes subsequent decomposition. Unlike energetic effects accompanying thermal transformations of the remaining compounds, the second step of the decomposition of the acid is exothermic (cf. DSC curve, Fig. 2). The exothermic reaction is probably due to conformational cis-aconitic anhydride $\rightarrow$ trans-aconitic anhydride transformation. This overweighing in excess endothermic effects of its further transformations.

These assumptions have subsequently been verified by the change of isomerization enthalpy, $\Delta H_{\text {isom. }}$, calculated using the DFT method. Its value for the conversion cis-aconitic anhydride $\rightarrow$ trans-aconitic anhydride is $\Delta H_{\text {isom. }}=$ $\mathrm{H}_{\text {trans }}-\mathrm{H}_{\text {cis }}=-30.66 \mathrm{~kJ} \mathrm{~mol}^{-1}$, where $H_{\text {trans }}$ and $H_{\text {cis }}$ denote enthalpies of the trans- and cis-isomers, respectively. The calculated free energy change, $\Delta G_{\text {isom. }}$, for the isomerization reaction is $-27.48 \mathrm{~kJ} \mathrm{~mol}^{-1}$.

The most probable thermal transformation pattern of the compounds studied is presented in Scheme 1. Decomposition of the compounds is a complex process leading through dehydration and decarboxylation reactions to different intermediate products. Due to similar structural features of the intermediate products, their identification is fairly difficult. The analysis of the volatiles using mass spectrometry revealed ions at $\mathrm{m} / \mathrm{z} 39$ and 68 in each case. However, they are characteristic of both the itaconic and citraconic anhydride. On the other hand, the IR spectra reveal that the decomposition of all the compounds studied affords identical products as demonstrated by bands at 1855 and $1794 \mathrm{~cm}^{-1}$ in the spectra of the volatiles, which are characteristic of cyclic acid anhydrides (Fig. 3). This, in turn, suggests that one of the final decomposition products is itaconic and/or citraconic anhydride.

In the MS spectra of the volatiles of all the samples studied, a ion with $\mathrm{m} / \mathrm{z}=112$ is present which is likely to be a molecular ion of either itaconic or citraconic anhydride. This conclusion seems to be correct, although the two anhydrides cannot be distinguished from each other under the conditions of the measurement.

In order to acquire a better knowledge of the thermal transformations of the compounds, kinetic characteristics of their decomposition would be needed. In view of the complexity of the process, determination of the mechanism and kinetics of the reactions using the techniques mentioned in our paper so far would be fairly difficult if not impossible. The reasons for this are the following (i) models describing the kinetics of the decomposition processes refer to single-step reactions. Consequently, attempts to fit a kinetic model using numerical methods that assume the least standard deviations as a criterion, in the case of complex processes, result in a description incompatible with reality; (ii) attempts to determine kinetic parameters of a reaction, i.e. activation energy, $E_{\mathrm{a}}$, or exponent in the Arrhenius equation (the Friedman or Ozawa-Flynn-Wall methods) would be charged with a huge error and their numerical values would not have a physical meaning. These reasons could explain discrepancies among the magnitudes of 
Scheme 1 Thermal transformations of citric acid, trans-aconitic acid and cisaconitic acid<smiles>O=C(O)C=C(CC(=O)O)C(=O)O</smiles>

citric acid<smiles>CC1=CC(=O)OC1=O</smiles>

$-\mathrm{CO}_{2}$

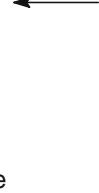<smiles>O=C(O)C=C1CC(=O)OC1=O</smiles>

trans-aconitic anhydride trans-aconitic acid<smiles>[3H][CH][13CH3]</smiles><smiles>O=CC(=CC(=O)O)C(=O)O</smiles>

cis-aconitic acid<smiles>O=C(O)C=C1CC(=O)OC1=O</smiles>

cis-aconitic anhydride
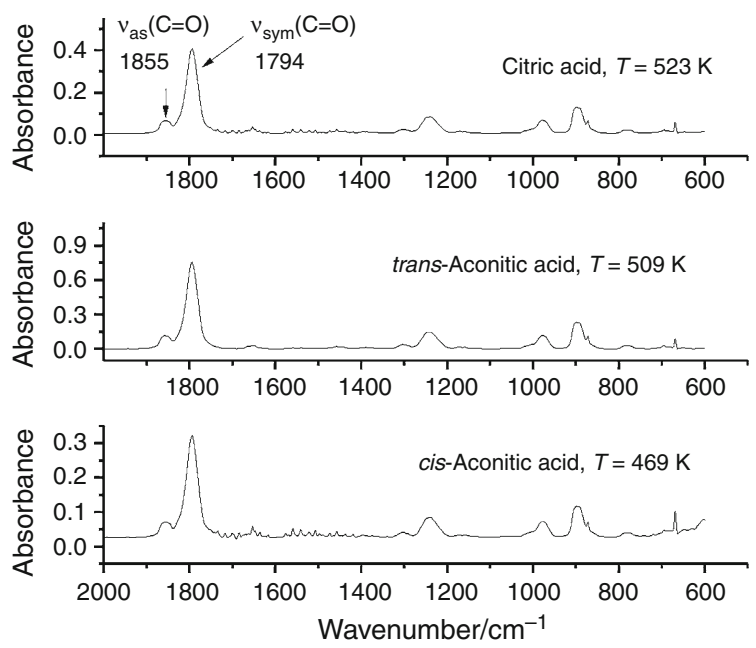

Fig. 3 IR spectra of the volatile products of the thermal decomposition of citric acid $(523 \mathrm{~K})$, trans-aconitic acid $(509 \mathrm{~K})$ and cisaconitic acid $(469 \mathrm{~K})$ in argon

activation energy reported in the literature for a particular compound when the process runs through a number of steps $[9,17]$. The discrepancies arise from the fact that $E_{\mathrm{a}}$ determined for multi-step processes refers to different elementary events depending on the extent of the reaction; (iii) for the dehydration reactions, which are usually reversible, the kinetics of decomposition depends on the partial pressure of water vapour over the sample being heated. For this reason, any description of the dehydration kinetics in the absence of a parallel measurement of the partial pressure variations in the oven seems to be inaccurate. This is because it is impossible to define the physical conditions of the measurement.

\section{Conclusions}

This article presents the thermal properties of citric acid, cis-aconitic acid and trans-aconitic acid determined in a neutral atmosphere (Ar) under different velocities of sample heating. The analysis of the DSC curves shows that only decomposition of citric acid is proceeded by the melting of the sample. The lowest thermal stability is exhibited by cis-aconitic acid undergoing dehydration at the first stage of decomposition, which leads to the formation of cis-aconitic anhydride. The presence of the exothermic peak on the DSC curve suggests that cisaconitic anhydride then undergoes isomerisation into transaconitic anhydride. In view of the lack of exothermic effects on the DSC curves of citric acid and trans-aconitic acid, it can be assumed that thermal transformations of both acids lead directly to the formation of trans-aconitic anhydride. The use of hyphenated techniques, i.e. TG-FTIR and TG-MS enabled a first time identification trial of the gaseous products resulting from decomposition of the acids studied. The analysis of the IR and MS spectra shows that the analyzed compounds undergo dehydration and decarboxylation leading to the formation of citraconic anhydride or itaconic anhydride or the mixture of both isomers regardless of the initial compound. In view of small differences in the structure of both compounds, it is not easy to identify any of the compounds on the basis of the obtained IR and MS spectra.

Acknowledgements This study was supported by the Polish Ministry of Science and Higher Education under grant DS/8230-4-0088-0. DFT calculations were conducted using the resources of 45-processor Beowulf cluster at the Faculty of Chemistry (University of Gdańsk) 
and the Informatics Computer Centre of the Metropolitan Academic Network (TASK, Gdańsk).

Open Access This article is distributed under the terms of the Creative Commons Attribution Noncommercial License which permits any noncommercial use, distribution, and reproduction in any medium, provided the original author(s) and source are credited.

\section{References}

1. Beinert H, Kennedy MC. Engineering of protein bound ironsulfur clusters. A tool for the study of protein and cluster chemistry and mechanism of iron-sulfur enzymes. Eur J Biochem. 1989;186:5-15.

2. Martin RB. Citrate binding of $\mathrm{Al}^{3+}$ and $\mathrm{Fe}^{3+}$. J Inorg Biochem. 1989;28:181-7.

3. Lippard SJ. Principles of bioinorganic chemistry. Mill Valley: University Science Books; 1994. p. 352.

4. Cushing BL, Kolesnichenko VL, O'Connor CJ. Recent advances in the liquid-phase syntheses of inorganic nanoparticles. Chem Rev. 2004;104:3893-946.

5. Matraszek A, Szczygieł I. Modified Pechini synthesis of $\mathrm{Na}_{3} \mathrm{Ce}\left(\mathrm{PO}_{4}\right)_{2}$ and thermochemistry of its phase transition. J Therm Anal Calorim. 2008;93:689-92.

6. da Silva MFP, de Souza Carvalho FM, da Silva Martins T, de Abreu Fantini MC, Isolani PC. The role of citrate precursors on the morphology of lanthanide oxides obtained by thermal decomposition. J Therm Anal Calorim. 2010;99:385-90.
7. Chai Y-L, Chang Y-S, Chen G-J, Hsiao Y-J. The effects of heattreatment on the structure evolution and crystallinity of $\mathrm{ZnTiO}_{3}$ nano-crystals prepared by Pechini process. Mater Res Bull. 2008; 43:1066-73.

8. Hardy A, Van Werde K, Vanhoyland G, Van Bael MK, Mullens J, Van Poucke LC. Study of the decomposition of an aqueous metalchelate gel precursor for $(\mathrm{Bi}, \mathrm{La}) 4 \mathrm{Ti}_{3} \mathrm{O}_{12}$ by means of TGA-FTIR TGA-MS and HT-DRIFT. Thermochim Acta. 2003;397:143-53.

9. Barbooti MM, Al-Sammerrai A. Thermal decomposition of citric acid. Thermochim Acta. 1986;98:119-26.

10. Par RG, Yang W. Density functional theory of atoms and molecules. New York: Oxford University Press; 1989.

11. Becke AD. Density-functional thermochemistry. III. The role of exact exchange. J Chem Phys. 1993;98:5648-52.

12. Lee C, Yang W. Development of the Colle-Salvetti correlationenergy formula into a functional of the electron density. Phys Rev. 1988;B37:785-9.

13. Jensen F. Introduction to computational chemistry. Chichester: Wiley; 1999.

14. Frisch MJ, et al. Gaussian 03, Revision C.02. Gaussian, Inc., Wallingford; 2004.

15. Matzapetakis M, Raptopoulou CP, Terzis A, Lakatos A, Kiss T, Salifoglou A. Synthesis, structural characterization, and solution behavior of the first mononuclear, aqueous aluminum citrate complex. Inorg Chem. 1999;38:618-9.

16. Wyrzykowski D, Chmurzyński L. Thermodynamics of citrate complexation with $\mathrm{Mn}^{2+}, \mathrm{Co}^{2+}, \mathrm{Ni}^{2+}$ and $\mathrm{Zn}^{2+}$ ions. J Therm Anal Calorim. 2009. doi:10.1007/s10973-009-0523-4.

17. Dollimore D, O'Connell C. A comparison of the thermal decomposition of preservatives, using thermogravimetry and rising temperature kinetics. Thermochim Acta. 1998;324:33-48. 